\title{
Structural and Crash Analysis of An Automobile Chassis
}

\author{
${ }^{1}$ Mohiddin Khan \\ M.Tech. Student: dept. of Mechanical Engineering \\ Raghu Engineering college, \\ Bheemunipatnam, Visakhapatnam, \\ Andhra Pradesh, pin code 531162, \\ India.
}

\begin{abstract}
The skeleton frames the fundamental structure of the cutting edge car. Countless plans in squeezed steel outline structure a skeleton on which the motor, wheels, hub congregations, transmission, directing instrument, brakes, and suspension individuals are mounted. During the assembling procedure the body is deftly rushed to the suspension. For vehicles, frame comprises of a get together of all the basic pieces of a truck (without the body) to be prepared for procedure out and about. In our undertaking, the displaying of body by utilizing CREO programming, by taking the information from the past diary paper for six-wheeler skeleton. Present utilized material for body is steel. The primary point is to supplant the body material steel with various steel amalgam (ASTM A710, ASTM A4130, MILD STEEL and STEEL ST 52) body materials. By utilizing steel, the heaviness of the case is more contrasted and steel compound (ASTM A710, ASTM A4130, MILD STEEL and STEEL ST 52) undercarriage. Crash investigation, Structural and irregular vibration examination is done on the body models ' $\mathrm{C}$ ' segment and rectangular box segment. Crash investigation to decide the pressure, disfigurement and strain while applying abrupt burden on the part. Static investigation to decide the twisting, proportionate anxiety to finding the quality of the segment when segment is in rest position. Modular investigation to decide the directional distortion, shear pressure and shear strain to discover the vibrations of undercarriage. 3D demonstrating in CREO and investigation in ANSYS programming.
\end{abstract}

Keywords: CREO, ASTM A710, ASTM A4130, MILD STEEL, STEEL ST 52, ANSYS, Crash investigation, Stress, Strain, Deformation, Static Analysis, Fatigue Analysis, Modal Analysis.

\section{INTRODUCTION}

The body shapes the primary structure of the cutting edge vehicle. An enormous number of structures in squeezed steel outline structure a skeleton on which the motor, wheels, hub congregations, transmission, guiding instrument, brakes, and suspension individuals are mounted. During the assembling procedure the body is deftly rushed to the body.This blend of the body and edge performs assortment of capacities. It ingests the responses from the developments of the motor and pivot, gets there activity powers of the wheels in speeding up and slowing down, retains streamlined breeze powers and street stuns through the suspension, and assimilates the significant vitality of effect in case of a mishap. There has been a steady move in present day little vehicle plans. There has been a pattern toward consolidating the undercarriage outline and the body into a solitary basic component. In this gathering, the steel body shell is fortified with supports that make it inflexible enough

\author{
*,2 Amit Kumar Mehar \\ Associate Professor: Dept. of Mechanical Engineering \\ Raghu Engineering college, \\ Bheemunipatnam, Visakhapatnam, \\ Andhra Pradesh, pin code 531162, \\ India.
}

to oppose the powers that are applied to it. To accomplish better clamor seclusion attributes, separate edges are utilized for different vehicles. The nearness of heavier-measure steel segments in current separate casing plans likewise will in general breaking point interruption in mishaps.

\section{CHASSIS FRAME:}

Undercarriage is a French expression and was at first used to mean the edge parts or Basic Structure of the vehicle. It is the foundation of the vehicle without body is called Chassis. The segments of the vehicle like Power plant, Transmission System, Axles, Wheels and tire, Suspension, Controlling Systems like Braking, Steering and so forth., and furthermore electrical framework parts are mounted on the Chassis outline. It is the primary mounting for all the parts including the body. So it is additionally called as Carrying Unit.

\subsection{Main Components}

The accompanying principle segments of the Chassis are 1. Casing: it is comprised of long two individuals assembled side individuals bolted with the assistance of number of cross individuals.

2. Motor or Power plant: It gives the source ofpower

3. Grasp: It interfaces and separates the force from the motor flywheel to the transmission framework.
4. Apparatus Box
5. U Joint
6. Propeller Shaft
7. Differential

\subsection{Functions of the Chassis Frame:}

1. To convey heap of the travelers or merchandise conveyed in the body.

2. To help the heap of the body, motor, gear box and so on.

3 . To withstand the powers caused because of the abrupt slowing down or speeding up

4. To withstand the anxieties caused because of the terrible street condition.

5. To withstand radiating power while cornering .

\subsection{Types of Chassis Edges:}

There are three kinds of edges

1. Regular edge

2. Necessary edge

3. Semi-necessary edge 


\section{STRUCTURE GOALS}

Undercarriage and Body Structure

The vehicle configuration fires up with reasonable examinations to characterize size, number and area of undriven and drive axles, kind of suspension, motor force, transmission, tire size and pivot decrease proportion, taxi size and assistant hardware. The chose setup must be reasonable for the considered transportation undertakings and should coordinate the current creation line. Either new vehicle type is produced or a specific improvement over existing sorts must be accomplished. In light of the furious rivalry, and trend setting innovation in building, assembling and administration and difficult work is required to be fruitful. Having characterized the overall arrangement of a vehicle, let us now focus the primary basic segments. The most significant capacity of the "spine" is supporting and disseminating the heaps beginning from.

- Payload including its vessels

- Axles with their installations

- coupling gadget

- Drive train

- Truck lodge including top sleeper/windshield

- Inertia powers

- constrained mishappening

- Special help capacities like taxi tilt system, freight taking care of

- Equipment

Not withstanding the essential auxiliary capacities, the undercarriage needs to join frill, discretionary and extraordinary gear like power through pressure, and electrical wiring and funneling frameworks. Out and out, space is extremely restricted and now and again just little cross area measurements are usable for the fundamental structure.

\section{LAYOUT OF CHASSIS AND ITS MAIN COMPONENTS}

"Skeleton" a French expression which implies the total Automobiles without Body and it incorporates all the frameworks like force plant, transmission, directing, suspension, wheels tires, auto electric framework and so forth without body. On the off chance that Body is additionally appended to it them it is referred to as the specific vehicle according to the shape and plan of the body

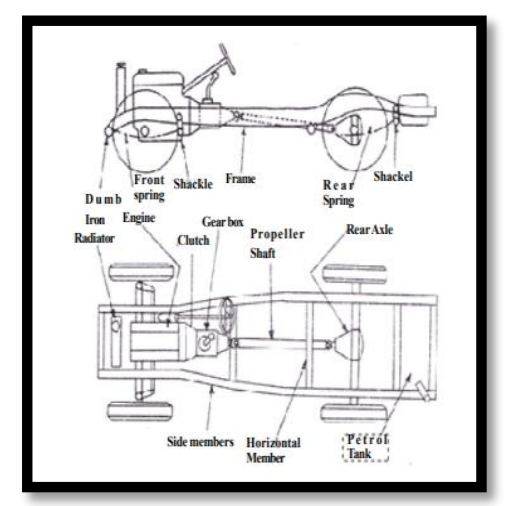

\subsection{Types of Chassis Frame sections}

1. Channel Section

2. Box Section

3. Tubular Section

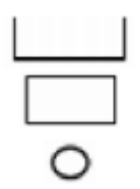

The regular edge is otherwise called Non-load conveying outline. In these sorts of casing, the heaps on the vehicle are moved to the suspension by the casing which is the primary skeleton of the vehicle. The direct area is utilized in long individuals and box segment in short individuals. Cylindrical area is utilized now-a-days is three wheelers, bikes, bullfighters and pickup vans. The edges ought to be sufficiently able to hold up under burden while abrupt brakes and mishaps.

\subsection{Various loads acting on the Chassis frame}

The heaps following up on the undercarriage outline are as follow

1. Fixed loads to be specific the heaps of lasting connection like all the pieces of the undercarriage, body and so forth.

2. Brief span loads while turning, slowing down and so on.

3. Transitory burdens while snappy increasing speed, abrupt slowing down and so on.

4. Burdens applied while going across streets of unpredictable and lopsided surfaces

5. Burdens brought about by abrupt mishaps, head on conspiracies and so on.

6. Burdens brought about by unpredictable and overburdening of vehicle.

\subsection{Conventional chassis or frame-full chassis}

You have heard "Undercarriage" much time in car yet till now you have disarray about it. In any case, Today I am going to inform you regarding it. Frame is the base of a vehicle. It comprise motor, transmission framework, slowing mechanism, suspension framework, guiding framework, cooling framework, wheels and so on.

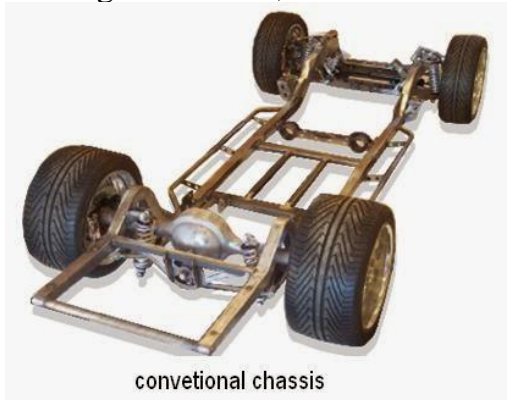

In this kind of case the body is made as a different unit and afterward got together with stepping stool outline. It underpins all the frameworks in a vehicle, for example, the Engine, Transmission framework, Steering framework, Suspension framework. 
Advantage Higher load capacity and strength

Disadvantage The body tends to vibrate easily and the overall vehicle handling and refinement is lower. It is used in truck, bus and in SUV cars and bigger vehicles.

\section{INTRODUCTION TO CREO}

PTC CREO, once in the past known as Pro/ENGINEER, is 3D displaying programming utilized in mechanical building, structure, producing, and in CAD drafting administration firms. It was one of the primary 3D CAD demonstrating applications that utilized a standard based parametric framework. Utilizing boundaries, measurements and highlights to catch the conduct of the item, it can enhance the advancement item just as the structure itself. The name was changed in 2010 from Pro/ENGINEER Wildfire to CREO. It was reported by the organization who created it, Parametric Technology Company (PTC), during the dispatch of its set-up of structure items that incorporates applications, for example, get together demonstrating, 2D orthographic perspectives for specialized drawing, limited component investigation and the sky is the limit from there.

\subsection{CREO parametric modules:}

- Sketcher

- $\quad$ Part modeling

- Assembly

- Drafting

\subsection{INTRODUCTION TO ANSYS}

ANSYS is broadly useful limited component examination (FEA) programming bundle. Limited Element Analysis is a numerical technique for deconstructing a mind boggling framework into extremely little bits (of client assigned size) called components. The product actualizes conditions that administer the conduct of these components and understands them all; making a complete clarification of how the framework goes about overall. These outcomes at that point can be introduced in arranged, or graphical structures. This kind of investigation is commonly utilized for the plan and improvement of a framework awfully complex to examine by hand. Frameworks that may fit into this class are excessively unpredictable because of their geometry, scale, or overseeing conditions. ANSYS gives a savvy approach to investigate the exhibition of items or procedures in a virtual situation. This kind of item advancement is named virtual prototyping. Structural investigation is presumably the most well-known utilization of the limited component strategy as it suggests extensions and structures, maritime, aeronautical, and mechanical structures, for example, transport frames, airplane bodies, and machine lodgings, just as mechanical segments, for example, cylinders, machine parts, and devices.

\section{STATIC ANALYSIS OF CHASSIS}

\section{Definition of Static Analysis}

A static examination ascertains the impacts of consistent stacking conditions on a structure, while overlooking inactivity and damping impacts, for example, those brought about by time-differing loads. A static examination can, in any case, incorporate consistent idleness loads, (for example, gravity and rotational speed), and time-changing burdens that can be approximated as static proportionate burdens, (for example, the static identical breeze and seismic loads generally characterized in many construction standards).

\subsection{Loads in a Static Analysis}

Static examination is utilized to decide the removals, stresses, strains, and powers in structures or segments brought about by loads that don't prompt huge idleness and damping impacts. Consistent stacking and reaction conditions are expected; that is, the heaps and the structure's reaction are accepted to differ gradually as for time. The sorts of stacking that can be applied in a static examination include: Externally applied forces and pressures

- Steady-state inertial forces (such as gravity or rotationalvelocity)

- Imposed (non-zero) displacements

- Temperatures (for thermal strain)

- Fluences (for nuclear swelling)

\subsection{Load Types}

\section{Displacements (UX, UY, UZ, ROTX, ROTY, ROTZ)}

These are DOF limitations typically indicated at model limits to characterize inflexible help focuses. They can likewise show evenness limit conditions and purposes of known movement. The bearings suggested by the marks are in the nodal facilitate framework.

\section{Forces (FX, FY, FZ) and moments (MX, MY, MZ)}

These are focused loads generally determined on the model outside. The bearings suggested by the names are in the nodal arrange framework.

\section{Pressures (PRES)}

These are surface burdens, additionally normally applied on the model outside. Positive estimations of weight act towards the component face (bringing about a compressive impact). Gravity, spinning, etc.

These are latency stacks that influence the whole structure. Thickness (or mass in some structure) must be characterized if latency impacts are to be incorporated.

\subsection{FINITE ELEMENT ANALYSIS OF CHASIS USING ANSYS WORKBENCH}

The model of undercarriage is spared in IGES design which can be legitimately brought into ANSYS workbench. The model imported to ANSYS workbench 


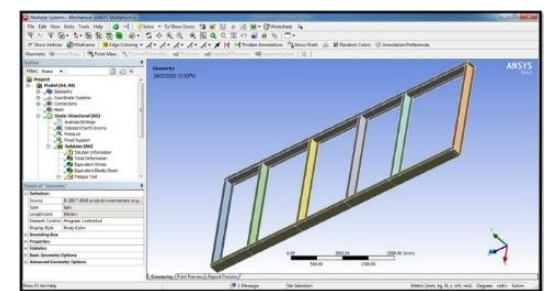

\subsubsection{Meshing and Boundary Conditions}

The meshing is done on the model with 3504 number of nodes and 10282 numbers of tetrahedral elements.

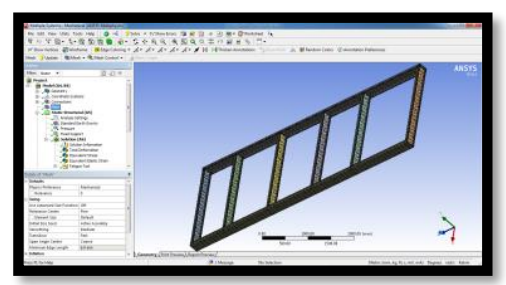

\subsubsection{Loads acting on the chassis}

The truck body model is stacked by static powers from the truck body and burden. For this model, the most extreme stacked load of truck in addition to body is $10,000 \mathrm{~kg}$. The heap is accepted as a uniform circulated got from the most extreme stacked weight partitioned by the all out length of suspension outline. The limited component model of the body, applied with limit conditions.

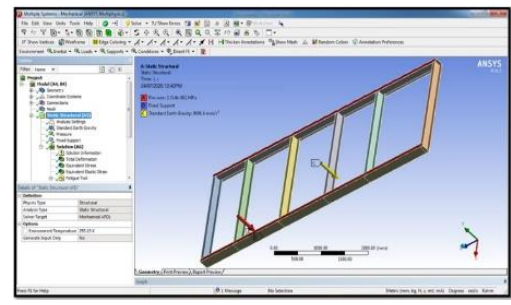

\subsubsection{SPECIFICATION OF MATERIAL}

\begin{tabular}{|l|l|l|l|l|}
\hline Properties & $\begin{array}{l}\text { ASTM } \\
\text { A4130 }\end{array}$ & $\begin{array}{l}\text { MILD } \\
\text { STEEL }\end{array}$ & $\begin{array}{l}\text { ASTM } \\
\text { A 710 }\end{array}$ & $\begin{array}{l}\text { STEEL } \\
\text { ST 52 }\end{array}$ \\
\hline Density $\left(\mathrm{g} / \mathrm{cm}^{3}\right)$ & 7.85 & 7.79 & 7.89 & 7.8 \\
\hline $\begin{array}{l}\text { Young's modulus } \\
\text { (MPa) }\end{array}$ & $\mathbf{8 0 0 0 0}$ & $\mathbf{7 8 0 0 0}$ & 190000 & 20000 \\
\hline Poisson's ratio & 0.29 & 0.33 & 0.29 & 0.29 \\
\hline
\end{tabular}

\section{CHASSIS TYPE -C-SECTION}

\subsection{Material- ASTM A4130 steel}

Deformation

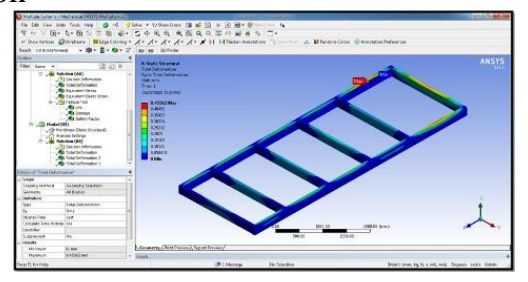

According to above plot the maximum deformation at one end of the chassis ladder beam, minimum deformation another ends of the chassis ladder. The red color indicating the maximum deformation and the blue color indicating the minimum deformation. The maximum deformation value $0.45562 \mathrm{~mm}$.

Stress

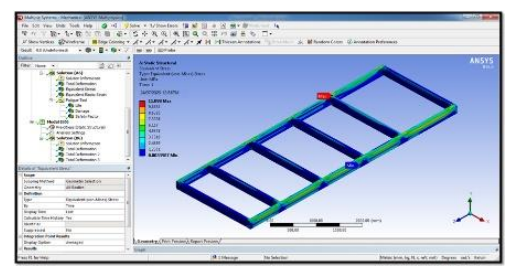

According g to above plot the maximum stress on the tro ladders of the chassis, minimum stress on the chassis beams. The maximum stress 11.098 mpa.

Strain

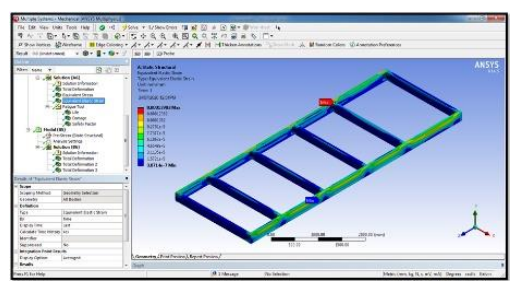

\subsubsection{Fatigue analysis of chassis}

Life

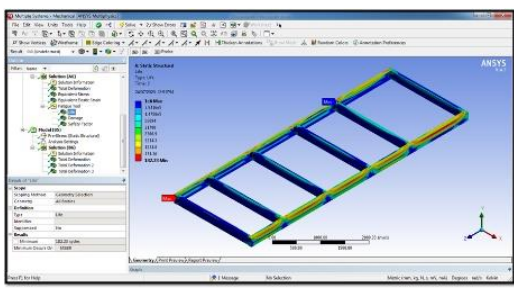

Damage

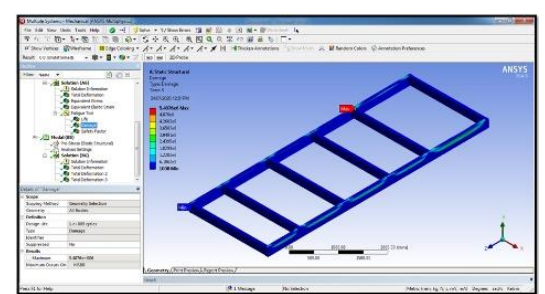

Safety factor

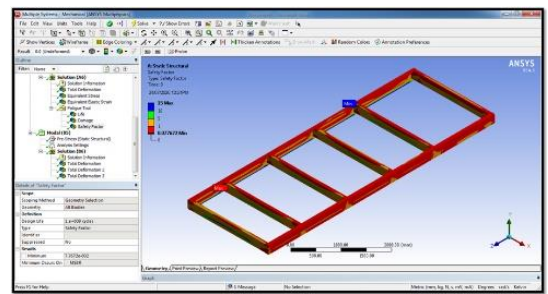

\subsubsection{Modal analysis of chassis}

Mode shape-1

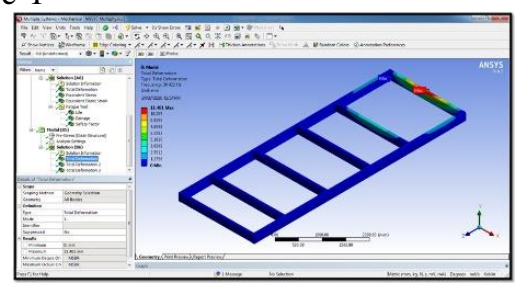


Mode shape-2

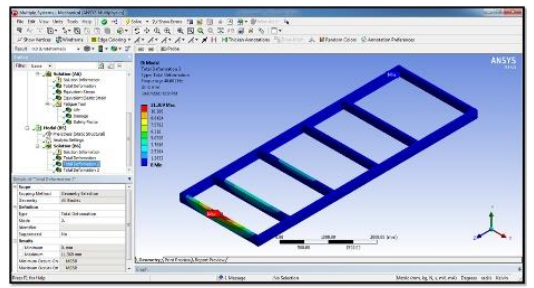

Mode shape-3

\subsection{Material- MILD STEEL}

Static analysis of chassis

Deformation

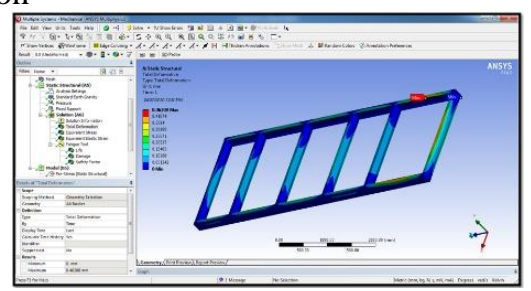

Stress

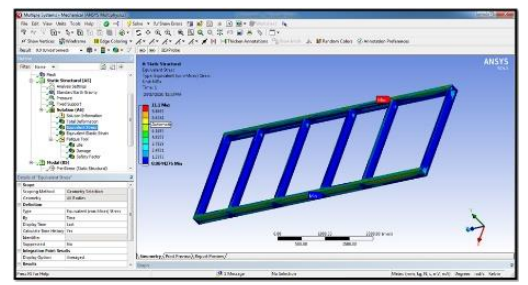

Strain

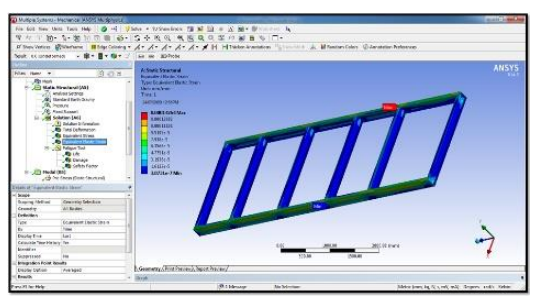

\subsubsection{Fatigue analysis of chassis}

Life

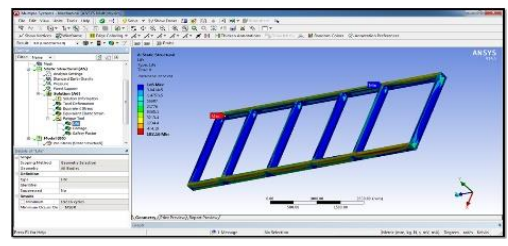

Damage

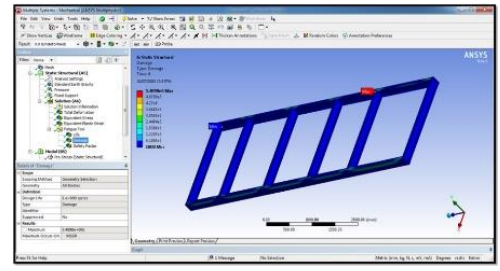

Safety factor

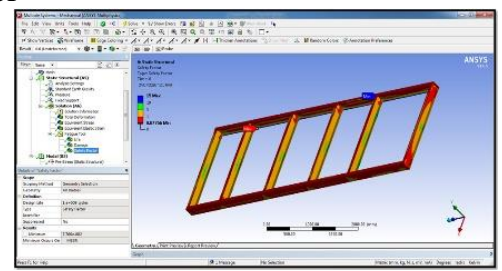

7.2.2 Modal analysis of chassis

Mode shape-1

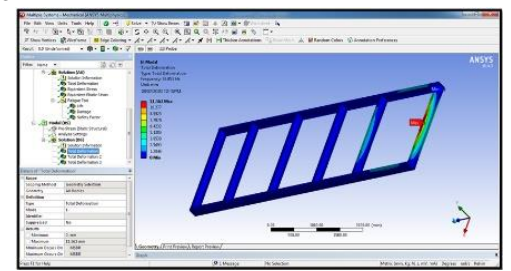

Mode shape-2

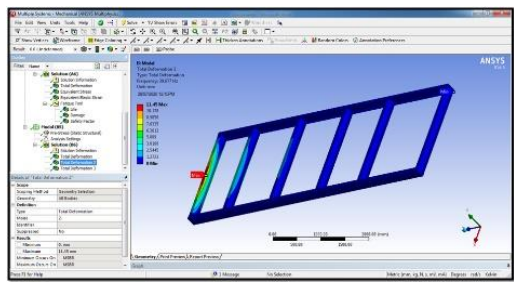

Mode shape-3

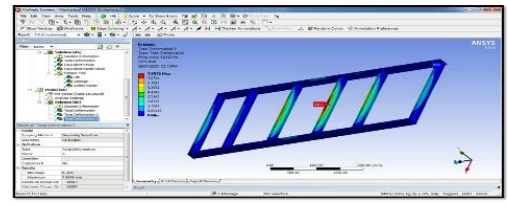

\subsection{Material- ASTM A710}

\subsubsection{Static analysis of chassis}

Deformation

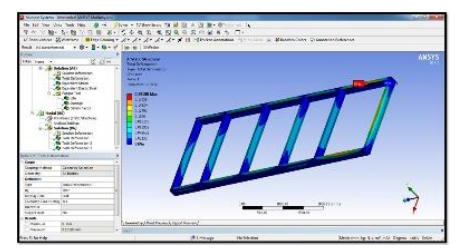

Stress 


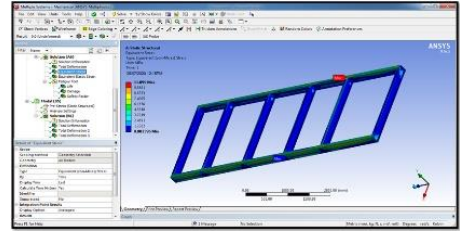

Strain

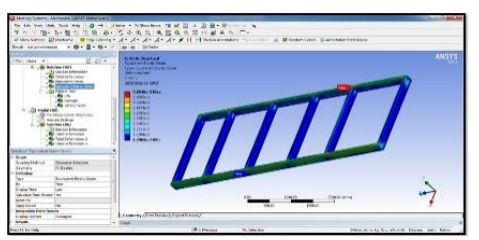

\subsubsection{FATIGUE ANALYSIS OF CHASSIS}

Fatigue is the weakening of a material caused by repeatedly applied loads. It is the progressive and localized structural damage that occurs when a material is subjected to cyclic loading. The nominal maximum stress values that cause such damage may be much less than the strength of the material typically quoted as the ultimate tensile stress limit, or the yield stress limit.

Life

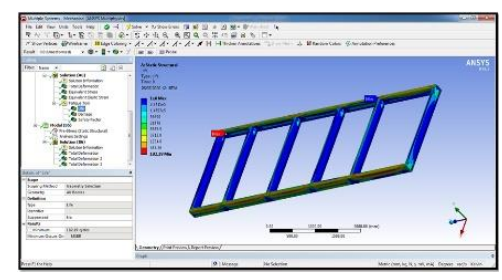

Damage

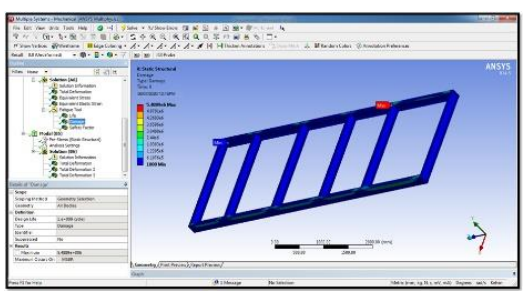

Safety factor

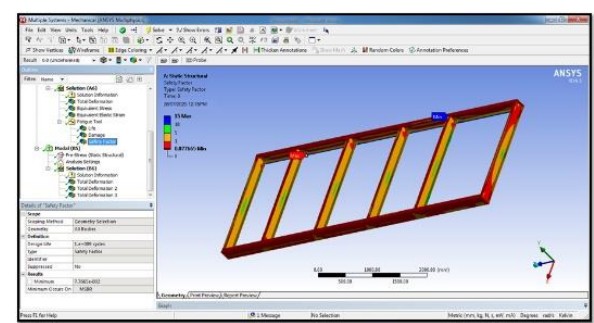

\subsubsection{Modal analysis of chassis}

Modal analysis to determine the vibration characteristics (natural frequencies and mode shapes) of a structure or a machine component while it is being designed. It also can be a starting point for another, more detailed, dynamic analysis, such as a transient dynamic analysis, a harmonic response analysis, or a spectrum analysis.

Mode shape-1

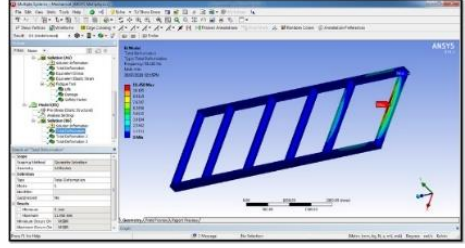

Mode shape-2

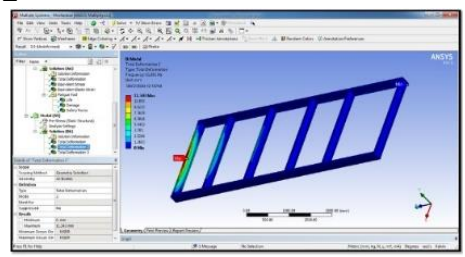

Mode shape-3

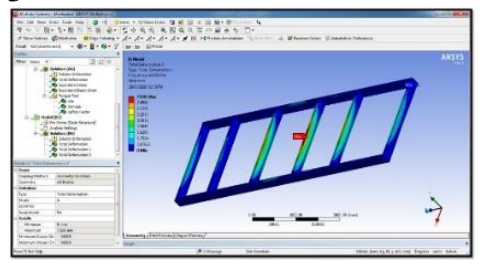

\subsection{Material- structural steel with ST52}

\subsubsection{Static analysis of chassis}

Deformation

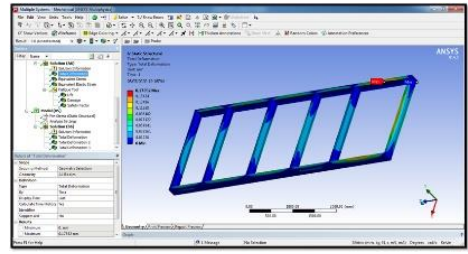

Stress

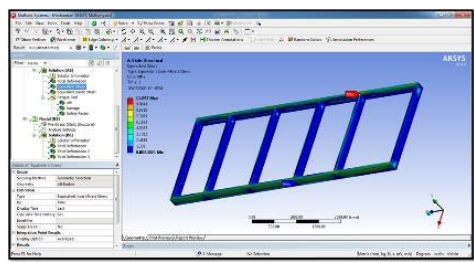

Strain

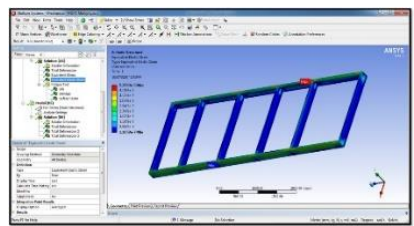

\subsubsection{Fatigue analysis of chassis}

Life

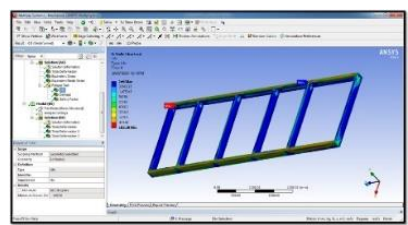


Damage

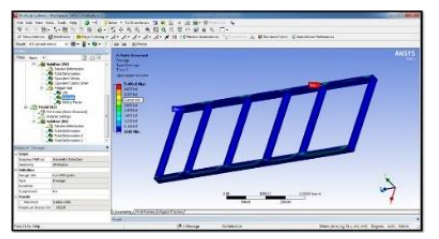

Safety factor

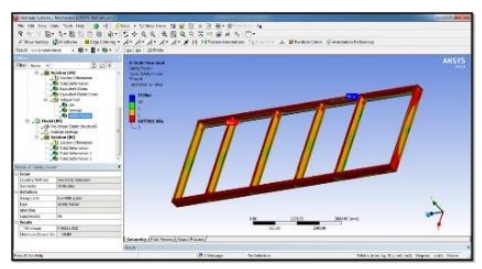

\subsubsection{Modal analysis of chassis}

Mode shape-1

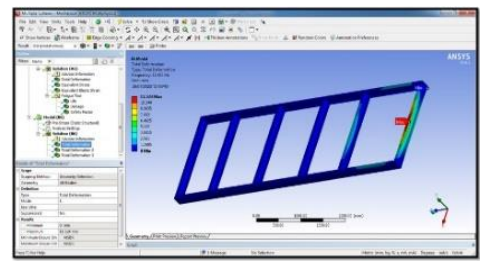

Mode shape-2

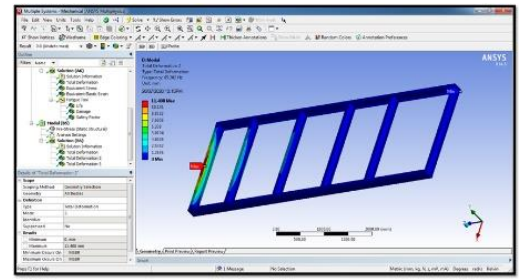

Mode shape-3

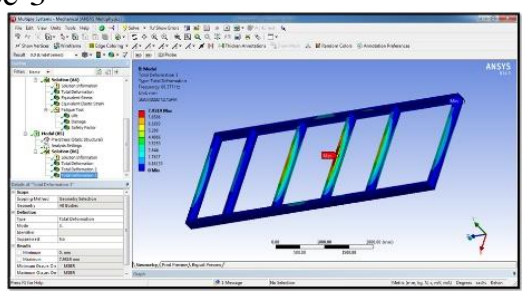

7.4.4 STATIC ANALYSIS RESULTS TABLE

\begin{tabular}{|l|l|l|l|}
\hline Material & Deformation(mm) & $\begin{array}{l}\text { Stress } \\
\text { (MPa) }\end{array}$ & Strain \\
\hline $\begin{array}{l}\text { ASTM } \\
\text { A4130 }\end{array}$ & $\mathbf{0 . 4 5 5 6 2}$ & 11.098 & $\mathbf{0 . 0 0 0 1 3 9 0 3}$ \\
\hline $\begin{array}{l}\text { MILD } \\
\text { STEEL }\end{array}$ & $\mathbf{0 . 4 6 2 0 8}$ & 11.1 & $\mathbf{0 . 0 0 0 1 4 2 6 4}$ \\
\hline $\begin{array}{l}\text { ASTM } \\
\text { A 710 }\end{array}$ & 0.19188 & 11.099 & $\mathbf{0 . 0 0 0 0 5 8 5 4 6}$ \\
\hline $\begin{array}{l}\text { STEEL } \\
\text { ST 52 }\end{array}$ & $\mathbf{0 . 1 7 3 5 2}$ & 11.097 & $\mathbf{0 . 0 0 0 0 5 2 9 5 9}$ \\
\hline
\end{tabular}

Here, from comparison of steel chassis with steel alloy chassis as shown in above table, it can be seen that the maximum deflection $0.46208 \mathrm{~mm}$ on MILD STEEL chassis and corresponding deflection in ASTM A4130, ASTM A710and STEEL ST 52 are $0.45562 \mathrm{~mm}, 0.19188$ $\mathrm{mm}$ and 0.17352. Also the von-misses stress in the MILD STEEL chassis $11.1 \mathrm{MPa}$ while in ASTM A4130, ASTM A710and STEEL ST 52 the von-misses stresses are 11.098 MPa, 11.099 MPa and 11.097 MPa respectively.

\subsubsection{DEFORMATION PLOT}

\section{deformation}

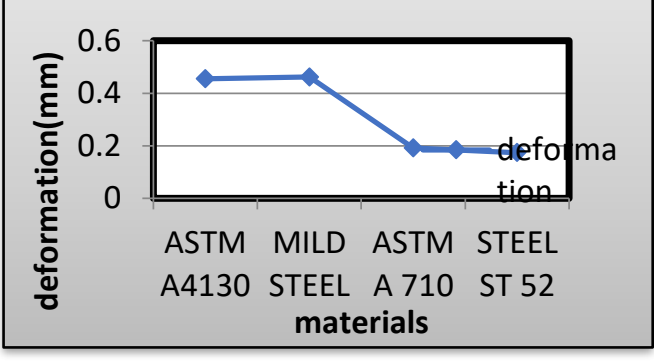

7.5.2 stress plot

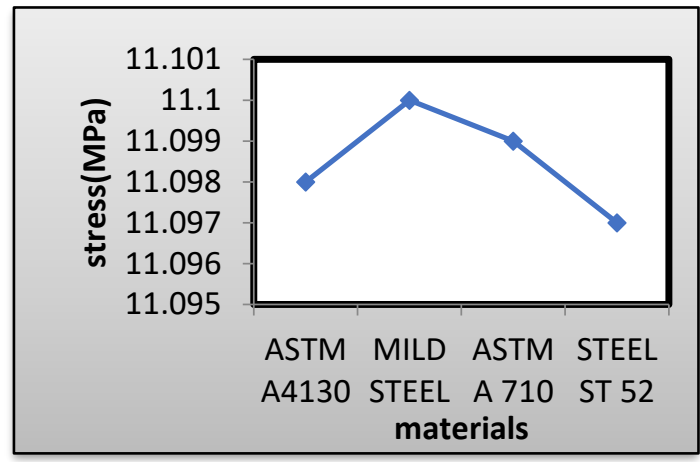

7.5.3 strain plot

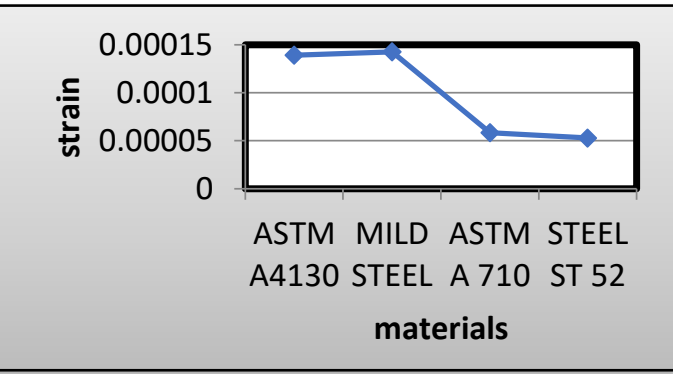

\subsubsection{ANALYSIS RESULTS TABLE}

\begin{tabular}{|c|c|c|c|}
\hline MATERIALS & $\begin{array}{l}\text { MODE } \\
\text { SHAPES }\end{array}$ & $\begin{array}{l}\text { DEFORMATION } \\
(\mathrm{mm})\end{array}$ & $\begin{array}{l}\text { Frequency } \\
\text { (Hz) }\end{array}$ \\
\hline \multirow[t]{3}{*}{ ASTM A4130 } & 1 & 11.481 & 38.422 \\
\hline & 2 & 11.369 & 40.081 \\
\hline & 3 & 7.8979 & 42.022 \\
\hline \multirow{3}{*}{$\begin{array}{l}\text { MILD } \\
\text { STEEL }\end{array}$} & 1 & 11.562 & 38.053 \\
\hline & 2 & 11.45 & 39.677 \\
\hline & 3 & 7.9576 & 41.612 \\
\hline \multirow[t]{3}{*}{ ASTM A710 } & 1 & 11.458 & 59.102 \\
\hline & 2 & 11.343 & 61.661 \\
\hline & 3 & 7.886 & 64.663 \\
\hline \multirow[t]{3}{*}{ STEEL ST 52} & 1 & 11.524 & 62.495 \\
\hline & 2 & 11.408 & 65.202 \\
\hline & 3 & 7.9319 & 68.377 \\
\hline
\end{tabular}




\subsubsection{FATIGUE ANALYSIS RESULTS}

\begin{tabular}{|l|l|l|l|l|}
\hline \multirow{2}{*}{ Material } & \multicolumn{2}{|l|}{ Life } & Damage & $\begin{array}{l}\text { Safety } \\
\text { factor }\end{array}$ \\
\cline { 2 - 4 } $\begin{array}{l}\text { MSTM } \\
\text { A4130 }\end{array}$ & $1 \times \mathrm{e}^{6}$ & $\mathbf{1 8 2 . 2 3}$ & $5.4876 \times \mathrm{e}^{6}$ & $\mathbf{0 . 0 7 7 6 7 2}$ \\
\hline $\begin{array}{l}\text { MILD } \\
\text { STEEL }\end{array}$ & $1 \times \mathrm{e}^{6}$ & 182.16 & $5.4898 \times \mathrm{e}^{6}$ & $\mathbf{0 . 0 7 7 6 6}$ \\
\hline $\begin{array}{l}\text { ASTM A } \\
710\end{array}$ & $1 \times \mathrm{e}^{6}$ & 182.19 & $5.4889 \times \mathrm{e}^{6}$ & $\mathbf{0 . 0 7 7 6 6 5}$ \\
\hline $\begin{array}{l}\text { STEEL } \\
\text { ST 52 }\end{array}$ & $1 \times \mathrm{e}^{6}$ & 182.28 & $5.486 \times \mathrm{e}^{6}$ & $\mathbf{0 . 0 7 7 6 8 1}$ \\
\hline
\end{tabular}

8. CHASSIS RECTANGULAR SECTION

\subsection{Material- ASTM A4130 steel}

\subsubsection{IMPORTED MODEL}

\section{MESHED MODEL}

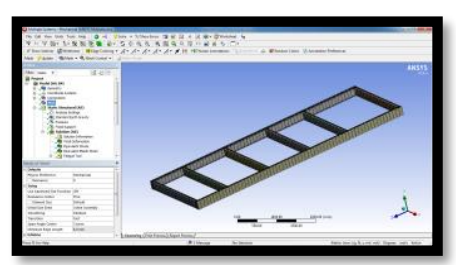

BOUNDARY CONDITIONS

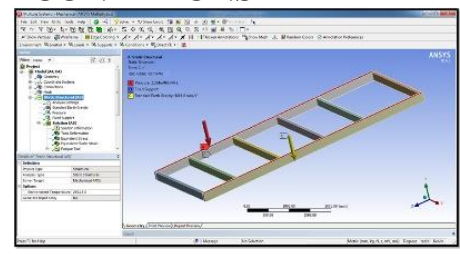

\subsubsection{Static analysis of chassis}

Deformation

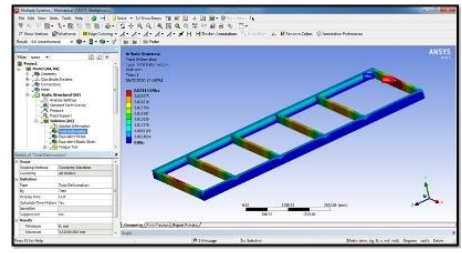

Stress

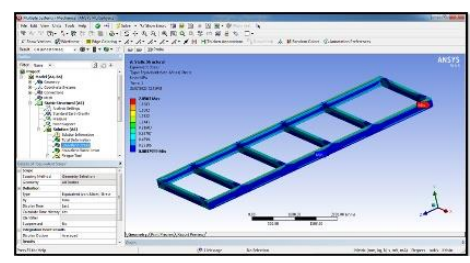

Strain

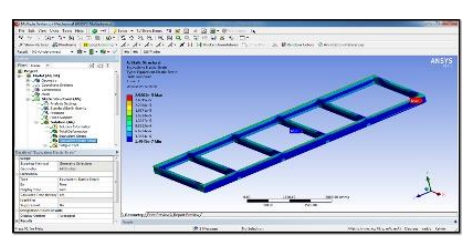

\subsubsection{Fatigue analysis of chassis}

Life

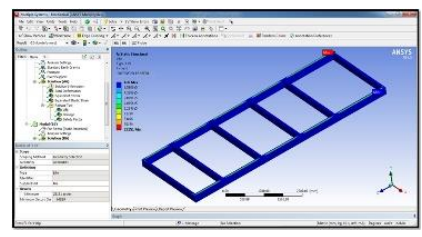

Damage

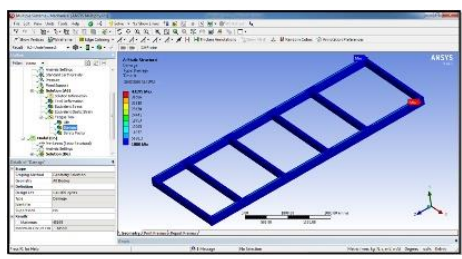

Safety factor

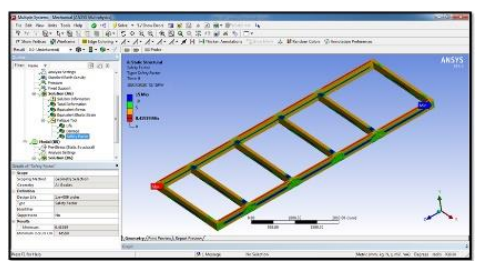

8.1.4 Modal analysis of chassis

Mode shape-1

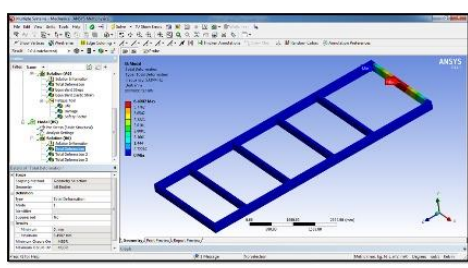

Mode shape-2

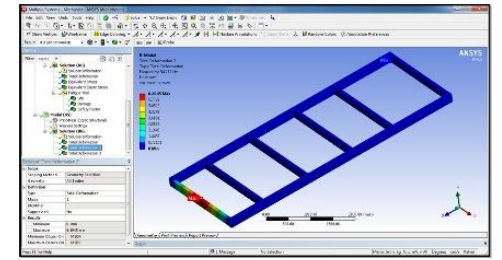

Mode shape-3

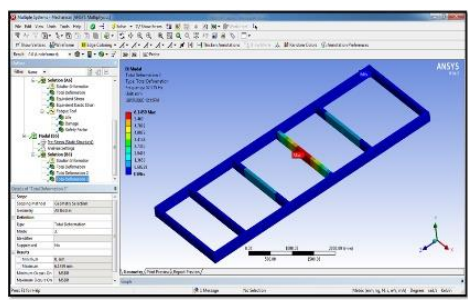




\section{Material- MILD STEEL}

\subsubsection{Static analysis of chassis}

Deformation

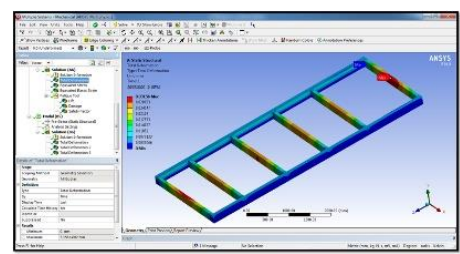

Stress

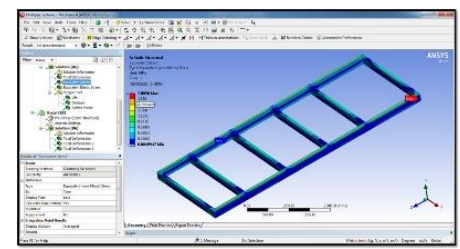

Strain

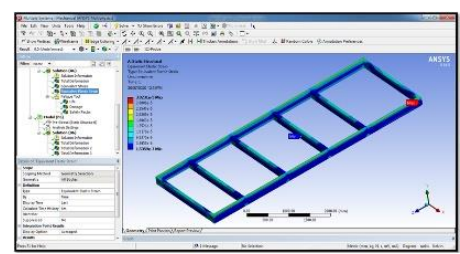

9.1.2 Fatigue analysis of chassis

Life

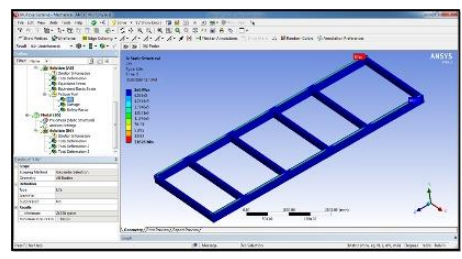

Damage

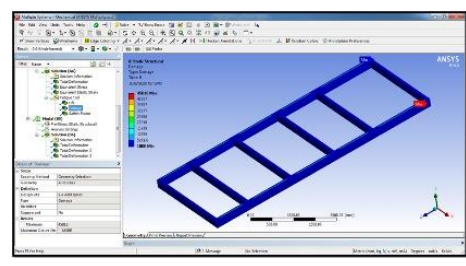

Safety factor

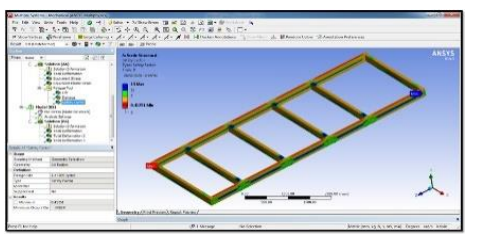

\subsubsection{Modal analysis of chassis}

Mode shape-1

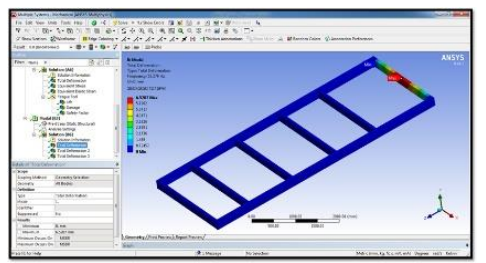

Mode shape-2

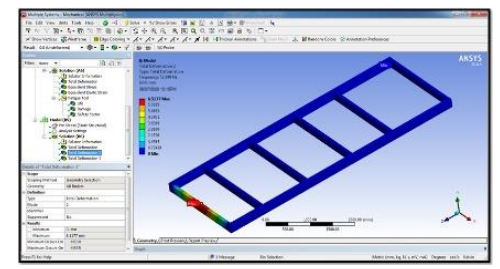

Mode shape-3

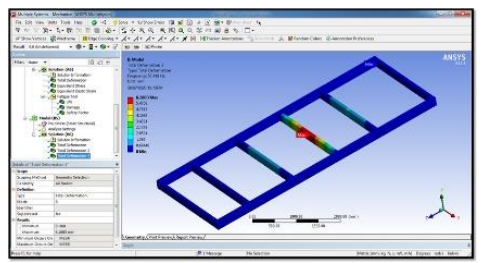

10.1Material- ASTM A710

10.1.1 Static analysis of chassis

Deformation

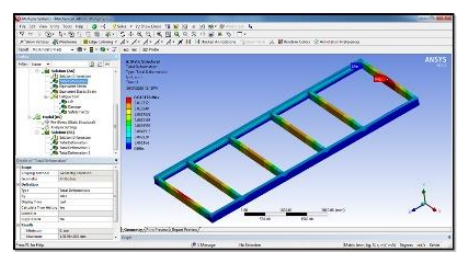

Stress

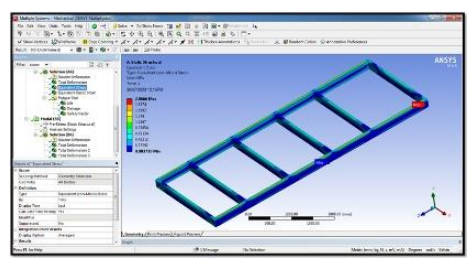

Strain

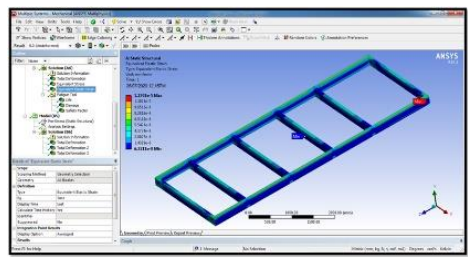




\subsubsection{Fatigue analysis of chassis}

Life

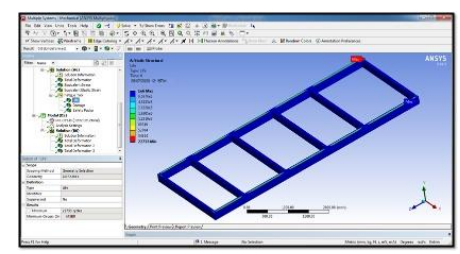

Damage

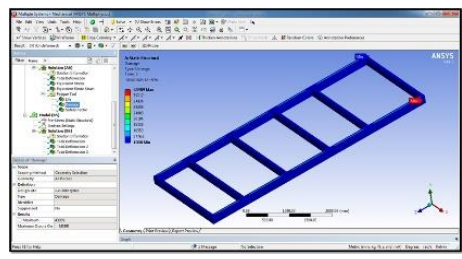

Safety factor

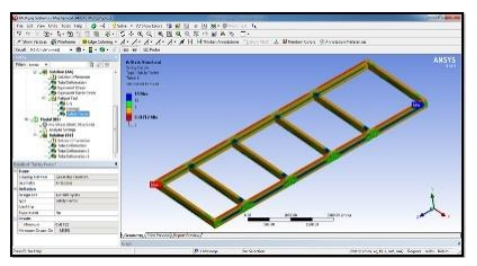

10.1.3 Modal analysis of chassis

Mode shape-1

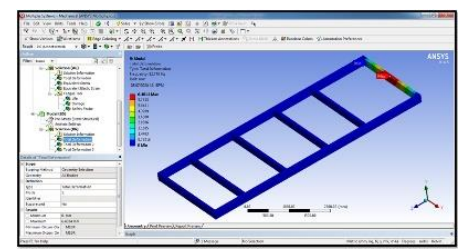

Mode shape-2

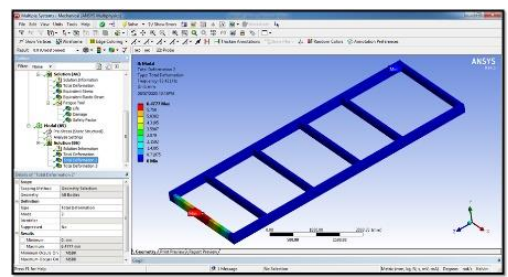

Mode shape-3

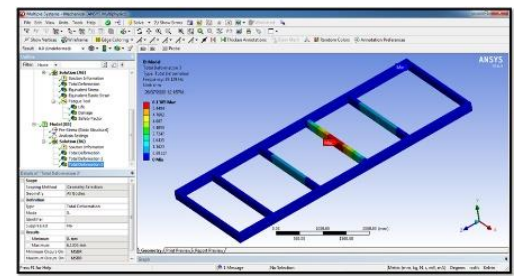

\subsection{Material- structural steel with ST52}

\subsubsection{Static analysis of chassis}

Deformation

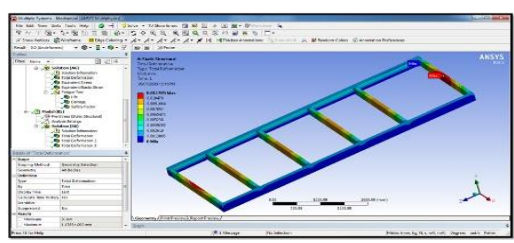

Stress

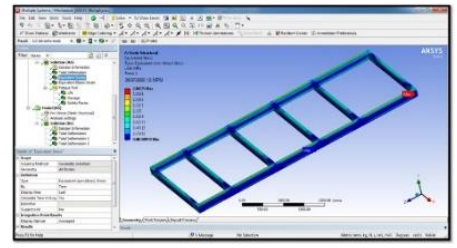

Strain

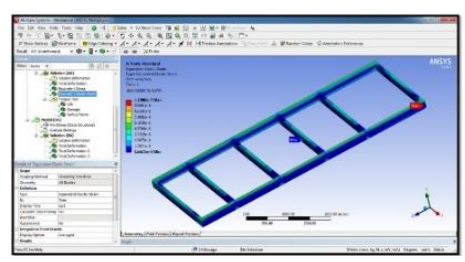

\subsubsection{Fatigue analysis of chassis}

Life

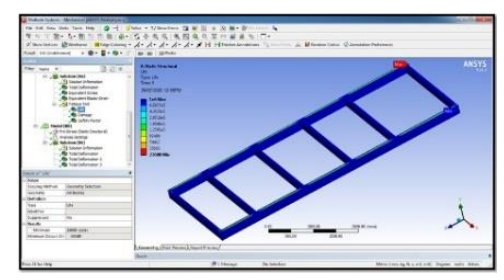

Damage

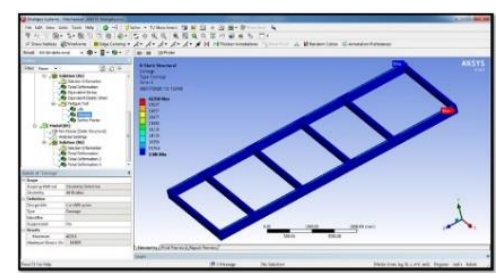

Safety factor

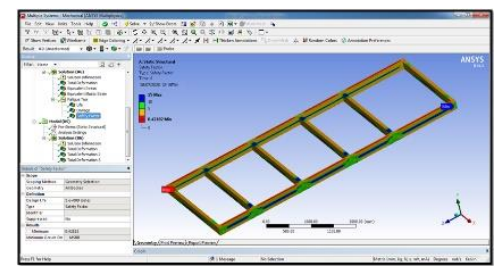


11.1.3 Modal analysis of chassis

Mode shape-1

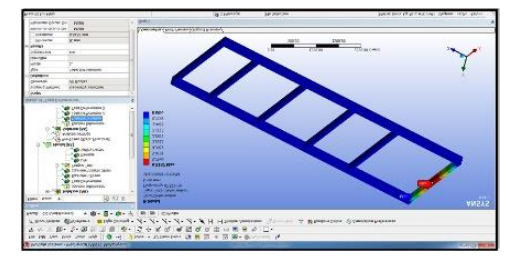

Mode shape-2

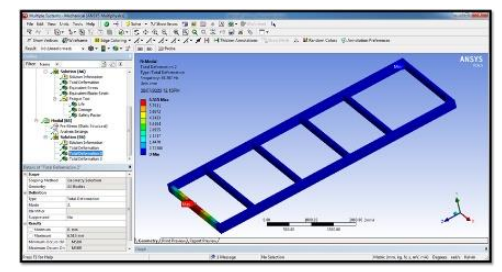

Mode shape-3

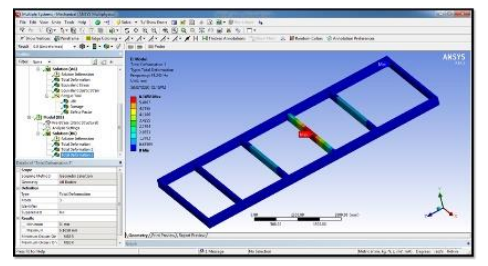

\subsection{STATIC ANALYSIS RESULTS TABLE}

\begin{tabular}{|l|l|l|l|}
\hline Material & Deformation(mm) & $\begin{array}{l}\text { Stress } \\
\text { (MPa) }\end{array}$ & Strain \\
\hline $\begin{array}{l}\text { ASTM } \\
\text { A4130 }\end{array}$ & $\mathbf{0 . 0 3 1 1 3 4}$ & $\mathbf{2 . 0 5 6 3}$ & $\mathbf{0 . 0 0 0 0 2 9 2 8 2}$ \\
\hline $\begin{array}{l}\text { MILD } \\
\text { STEEL }\end{array}$ & 0.03156 & 2.0896 & 0.000030231 \\
\hline $\begin{array}{l}\text { ASTM } \\
\text { A 710 }\end{array}$ & $\mathbf{0 . 0 1 3 1 7 6}$ & 2.0666 & $\mathbf{0 . 0 0 0 0 1 2 3 9 1}$ \\
\hline $\begin{array}{l}\text { STEEL } \\
\text { ST 52 }\end{array}$ & 0.011785 & 2.0435 & $\mathbf{0 . 0 0 0 0 1 1 0 8 6}$ \\
\hline
\end{tabular}

\subsection{DEFORMATION PLOT}

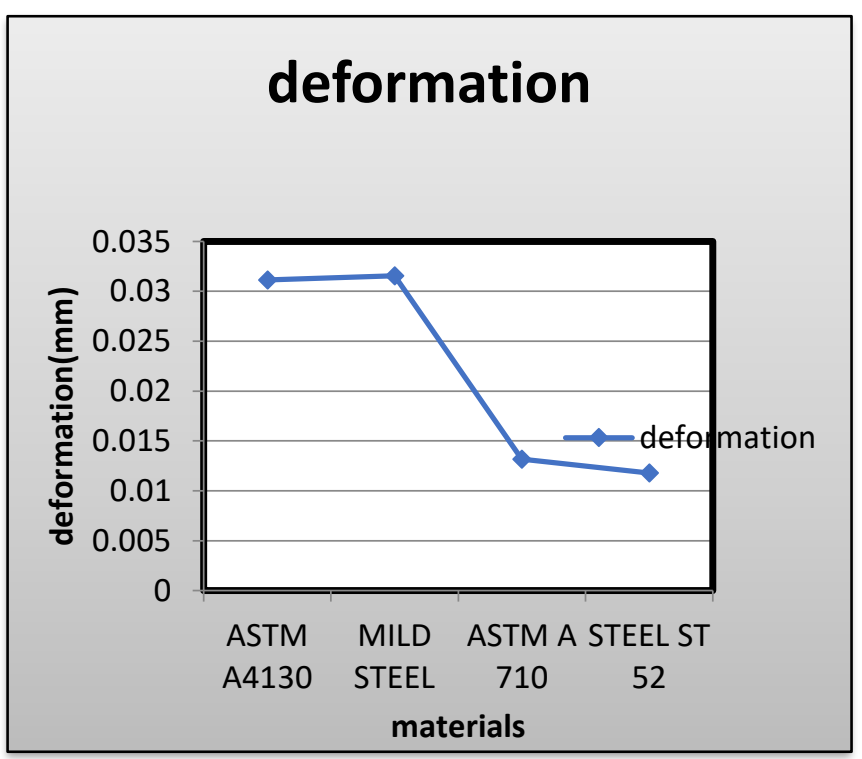

11.4 stress plot

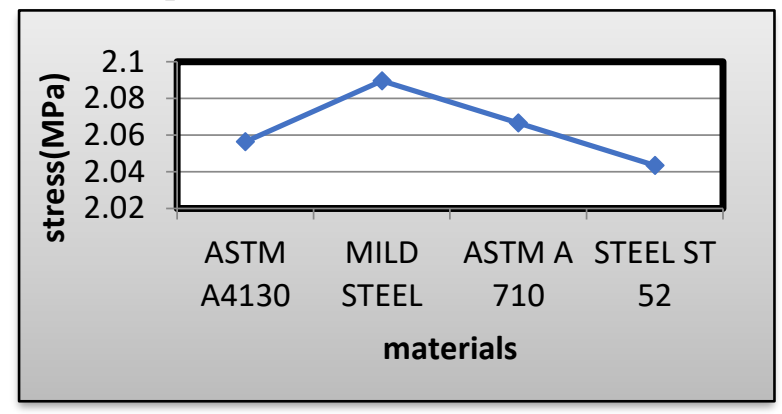

11.5 strain plot

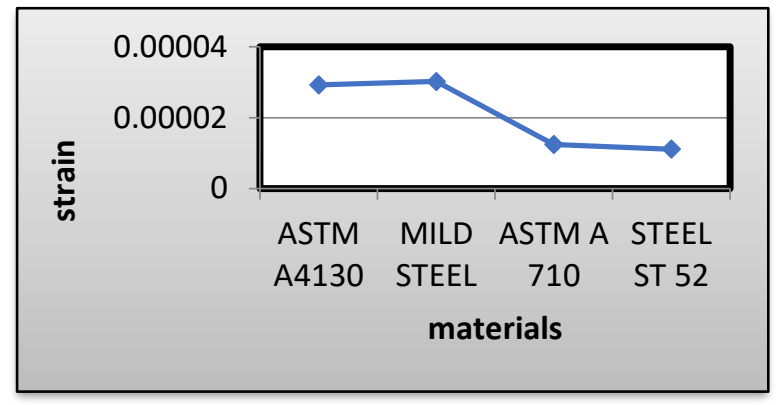

11.6 MODAL ANALYSIS RESULTS TABLE

\begin{tabular}{|c|c|c|c|}
\hline MATERIALS & $\begin{array}{l}\text { MODE } \\
\text { SHAPES }\end{array}$ & $\begin{array}{l}\text { DEFORMATION } \\
(\mathrm{mm})\end{array}$ & $\begin{array}{l}\text { Frequency } \\
(\mathrm{Hz})\end{array}$ \\
\hline \multirow[t]{3}{*}{ ASTM A4130 } & 1 & 6.4982 & 53.844 \\
\hline & 2 & 6.4945 & 54.262 \\
\hline & 3 & 6.1459 & $\mathbf{5 7 . 9 7 5}$ \\
\hline \multirow{3}{*}{$\begin{array}{l}\text { MILD } \\
\text { STEEL }\end{array}$} & 1 & 6.5207 & $\begin{array}{l}53.278 \\
\end{array}$ \\
\hline & 2 & 6.5177 & 53.688 \\
\hline & 3 & 6.1603 & 57.419 \\
\hline \multirow[t]{3}{*}{ ASTM A 710} & 1 & 6.488 & 82.779 \\
\hline & 2 & 6.4777 & 83.421 \\
\hline & 3 & 6.1305 & 89.129 \\
\hline \multirow[t]{3}{*}{ STEEL ST 52} & $\mathbf{1}$ & 6.5187 & 87.529 \\
\hline & 2 & 6.515 & 88.207 \\
\hline & 3 & 6.1658 & 94.242 \\
\hline
\end{tabular}

11.6.1 FATIGUE ANALYSIS RESULTS

\begin{tabular}{|l|l|l|l|l|}
\hline \multirow{2}{*}{ Material } & \multicolumn{2}{|l|}{ Life } & Damage & $\begin{array}{l}\text { Safety } \\
\text { factor }\end{array}$ \\
\cline { 2 - 3 } $\begin{array}{l}\text { ASTM } \\
\text { A4130 }\end{array}$ & $1 \times \mathbf{e}^{6}$ & $\mathbf{2 3 1 5 1}$ & 43195 & 0.41919 \\
\hline $\begin{array}{l}\text { MILD } \\
\text { STEEL }\end{array}$ & $1 \times \mathbf{e}^{6}$ & 21826 & 45816 & 0.41251 \\
\hline $\begin{array}{l}\text { ASTM A } \\
710\end{array}$ & $1 \times \mathbf{e}^{6}$ & 22733 & 43.989 & 0.41712 \\
\hline $\begin{array}{l}\text { STEEL } \\
\text { ST 52 }\end{array}$ & $1 \times \mathbf{e}^{6}$ & 23688 & 42216 & $\mathbf{0 . 4 2 1 8 2}$ \\
\hline
\end{tabular}

12. CRASH ANALYSIS OF C-SECTION CHASSIS

12.1 Material- ASTM A4130 steel

\section{IMPORTED MODEL}

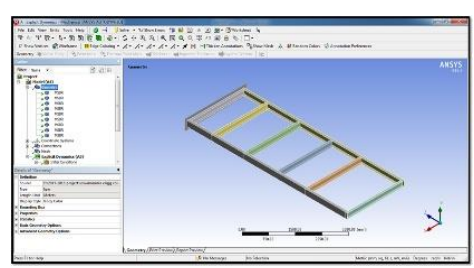




\section{MESHED MODEL}

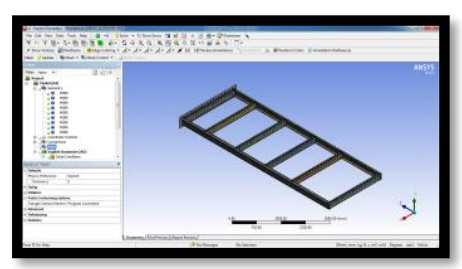

BOUNDARY CONDITIONS

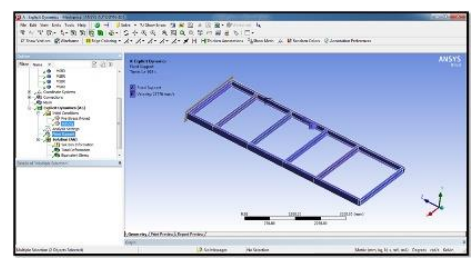

Deformation

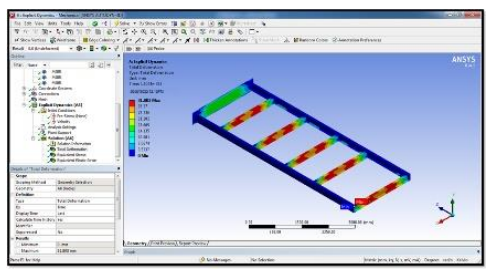

Stress

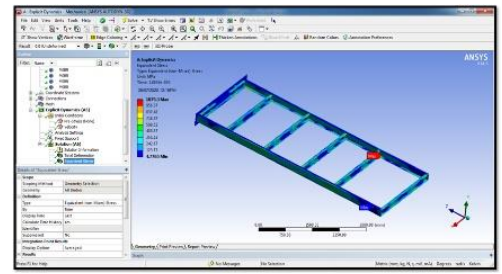

Strain

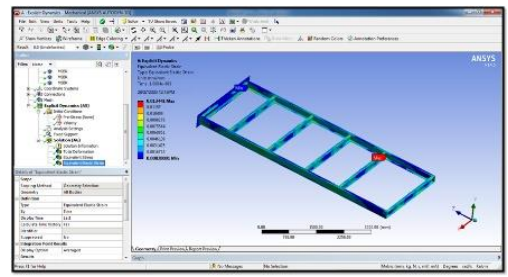

12.2 Material- MILD STEEL

Deformation

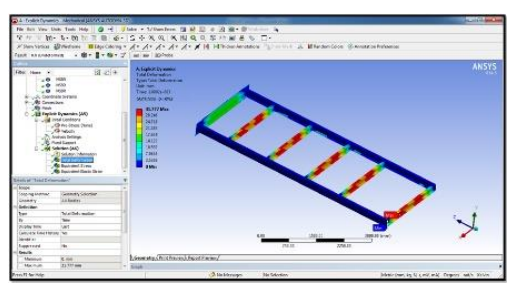

Stress

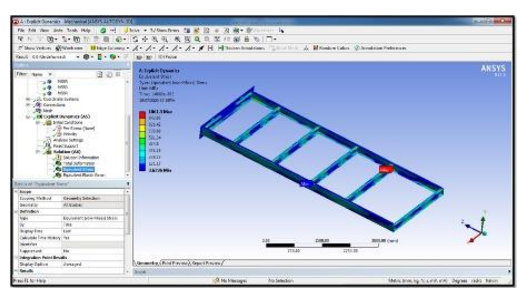

Strain

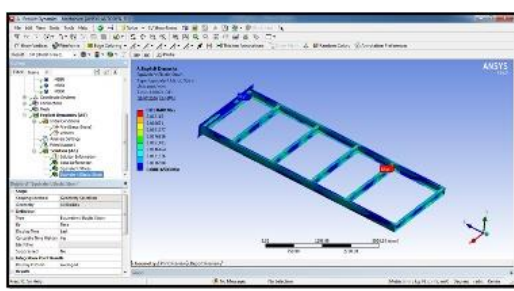

12.3 Material- ASTM A710

Deformation

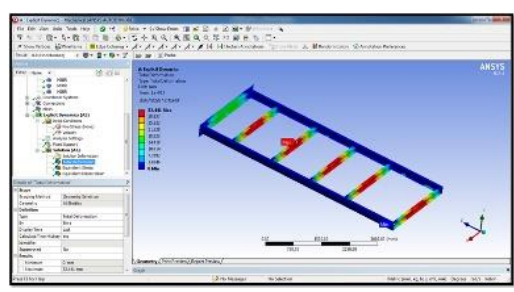

Stress

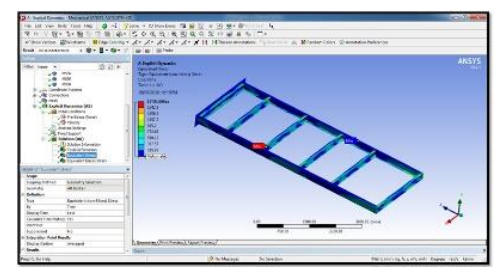

Strain

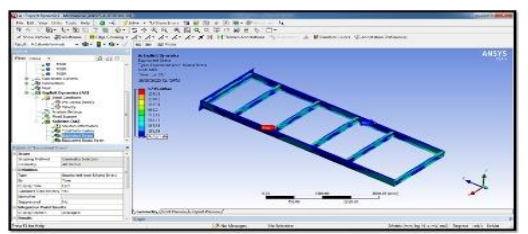

12.4 Material- structural steel with ST52

Deformation

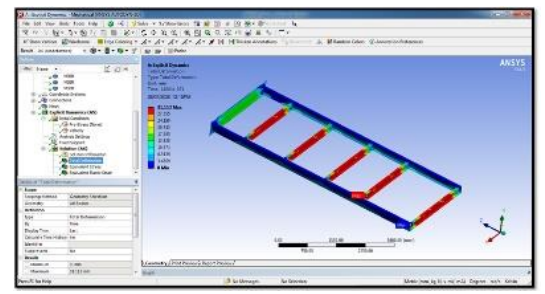


Stress

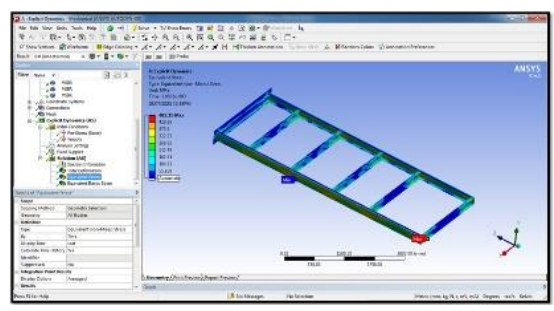

Strain

\begin{tabular}{|l|l|l|l|}
\hline & \multicolumn{3}{|c|}{} \\
\hline \begin{tabular}{l}
\hline \\
Material \\
A4130
\end{tabular} & Deformation(mm) & $\begin{array}{l}\text { Stress } \\
\text { (MPa) }\end{array}$ & Strain \\
\hline $\begin{array}{l}\text { MILD } \\
\text { STEEL }\end{array}$ & 31.803 & 1075.3 & 0.013441 \\
\hline $\begin{array}{l}\text { ASTM A } \\
\text { 710 }\end{array}$ & 32.441 & 1061.5 & 0.013609 \\
\hline $\begin{array}{l}\text { STEEL ST } \\
\text { 52 }\end{array}$ & 31.112 & 1735.4 & 0.0091565 \\
\hline
\end{tabular}

Here, from comparison of steel chassis with steel alloy chassis as shown in above table, it can be seen that the maximum deflection $32.441 \mathrm{~mm}$ on ASTM A710chassis and corresponding deflection in ASTM A4130, MILD STEEL and STEEL ST 52 are $31.803 \mathrm{~mm}, 31.777 \mathrm{~mm}$ and $31.112 \mathrm{~mm}$. Also the von-misses stress in the ASTM A710chassis $1735.4 \mathrm{MPa}$ while in ASTM A4130, MILD STEEL and STEEL ST 52 the von-misses stresses are 1075.3 MPa, 1061.5 MPa and 482.15 MPa respectively.

\subsection{1 stress plot}

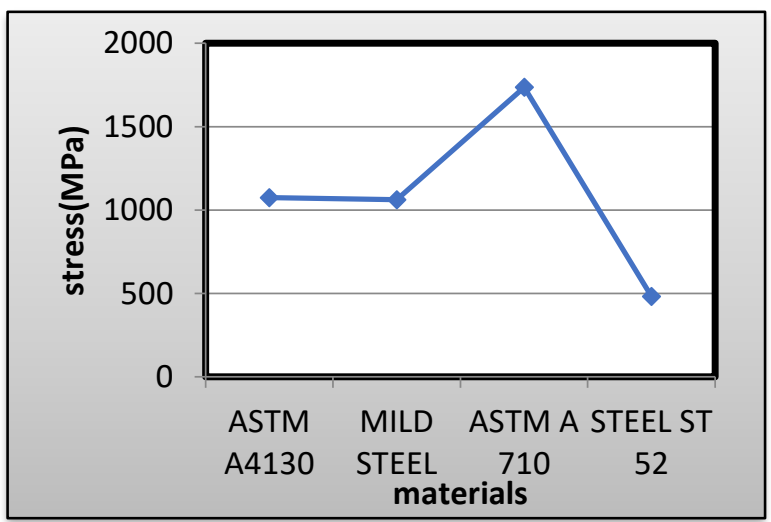

12. CRASH ANALYSIS OF RECTANGULARSECTION CHASSIS

\subsection{Material- ASTM A4130 steel}

Deformation

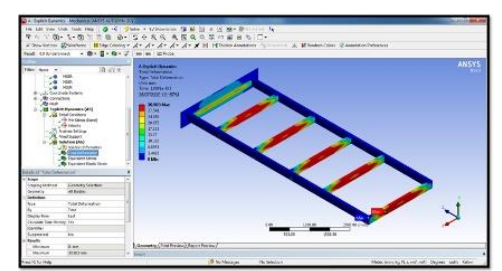

Stress

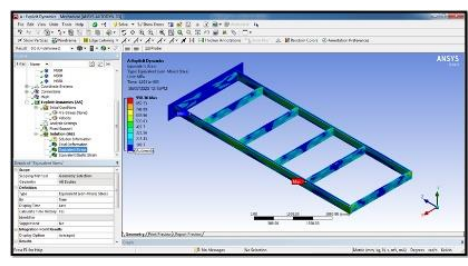

Strain

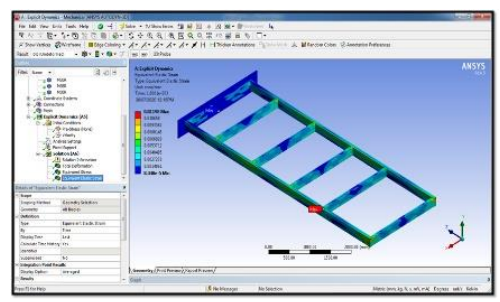

13.2 Material- MILD STEEL

Deformation

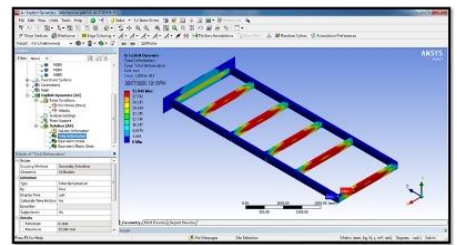

Stress

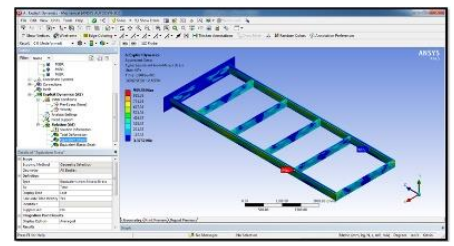

Strain

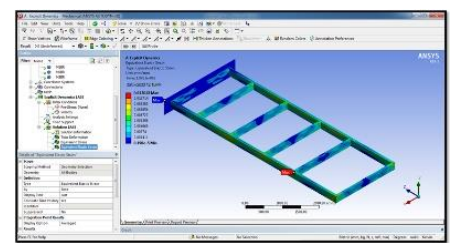




\subsection{Material- ASTM A710}

Deformation

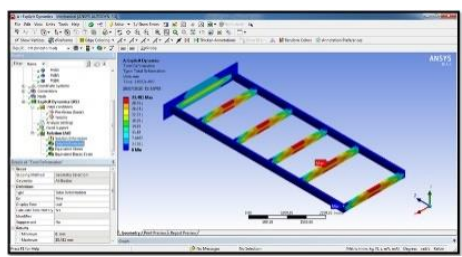

Stress

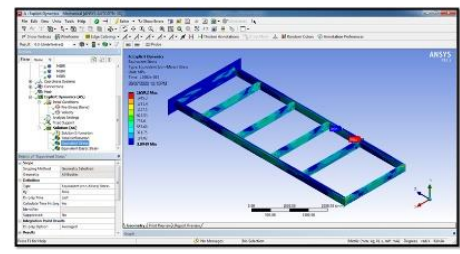

Strain

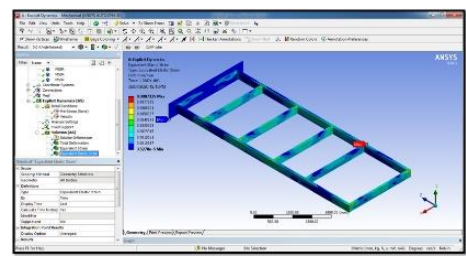

12.4 Material- structural steel with ST52

Deformation

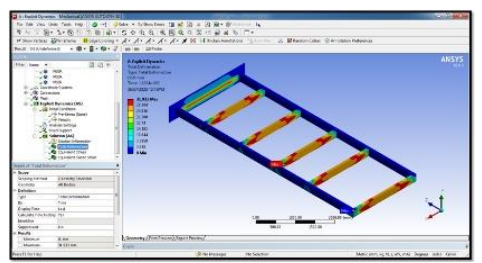

Stress

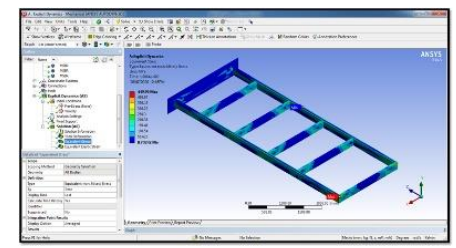

Strain

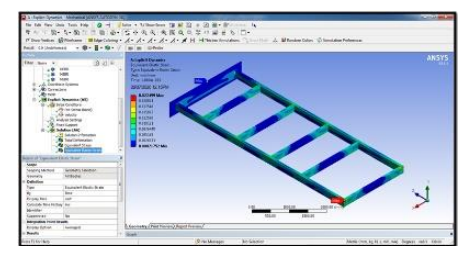

13.5 STATIC ANALYSIS RESULTS TABLE

\begin{tabular}{|l|l|l|l|}
\hline Material & Deformation(mm) & $\begin{array}{l}\text { Stress } \\
\text { (MPa) }\end{array}$ & Strain \\
\hline $\begin{array}{l}\text { ASTM } \\
\text { A4130 }\end{array}$ & 30.983 & 958.36 & 0.01198 \\
\hline $\begin{array}{l}\text { MILD } \\
\text { STEEL }\end{array}$ & 31.041 & 939.35 & 0.012043 \\
\hline $\begin{array}{l}\text { ASTM } \\
\text { A710 }\end{array}$ & $\mathbf{3 3 . 4 8 1}$ & 1659.2 & $\mathbf{0 . 0 0 8 7 3 2 9}$ \\
\hline $\begin{array}{l}\text { STEEL ST } \\
\text { 52 }\end{array}$ & 31.932 & 449.99 & 0.022499 \\
\hline
\end{tabular}

Here, from comparison of steel chassis with steel alloy chassis as shown in above table, it can be seen that the maximum deflection $33.481 \mathrm{~mm}$ on ASTM A710chassis and corresponding deflection in ASTM A4130, MILD STEEL and STEEL ST 52 are $30.983 \mathrm{~mm}, 31.041 \mathrm{~mm}$ and $31.932 \mathrm{~mm}$. Also the von-misses stress in the ASTM A710chassis 1659.2 MPa while in ASTM A4130, MILD STEEL and STEEL ST 52 the von-misses stresses are 958.36 MPa, 939.35 MPa and 449.99 MPa respectively.

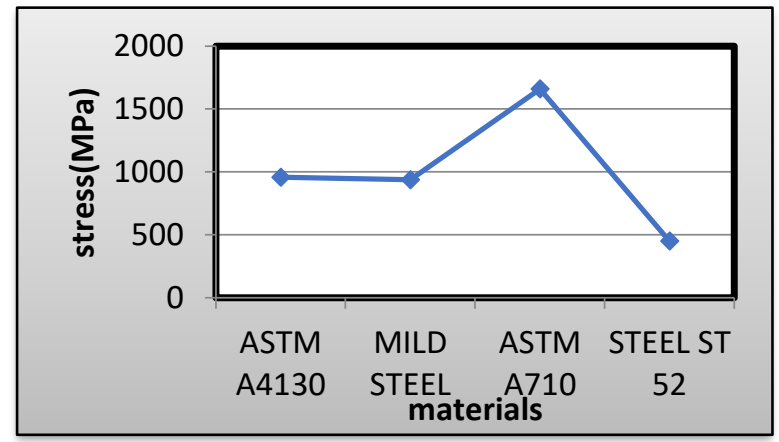

13. FUTURE SCOPE OF WORK

Analysis should be possible on undercarriage by changing the fiber direction of composite material.

It can be gotten by doing the investigation with metal lattice composite skeleton.

\section{CONCLUSION}

The plan and static auxiliary investigation of steel composite case has been done. Correlation has been made between csegment and rectangular area suspension having same materials and same burden conveying limit. The pressure and relocations have been determined utilizing hypothetically just as utilizing ANSYS for steel composite (ASTM A710, ASTM A4130, MILD STEEL and STEEL ST 52) skeleton. A relative report has been made between $\mathrm{c}$ segment and rectangular segment as for quality and weight. from the above outcomes the rectangular area skeleton having less pressure when we think about the c-segment case and having less pressure ASTM A710steel. 


\section{REFERENCES}

[1] Abhishek Singh, et al, "Assistant Analysis of Ladder Chassis for Higher Strength", International Journal of Emerging Technology and Advanced Engineering, ISSN: 2250-2459, Volume 4, Issue 2, February 2014.

[2] Patel Vijaykumar, et al, "Assistant Analysis of Automotive Chassis Frame and Design Modification for Weight Reduction", International Journal of Engineering Research and Technology, ISSN: 2278-0181, Volume 1, Issue 3, May 2012.

[3] Vishal Francis, et al, "Assistant Analysis of Ladder Chassis Frame for Jeep Using Ansys", International Journal of Modern Engineering Research, ISSN: 2249-6645, Volume 4, Issue 4, April 2014.

[4] Monika S.Agarwal, et al, "Limited Element Analysis of Truck Chassis", International Journal of Engineering Sciences and Research, ISSN: 2277-9655, December 2013.

[5] Vijaykumar V. Patel and R.I. Patel, "auxiliary examination of stepping stool body outline", ISSN 2231 2581, Mechanical office, Government building school, Gujrat.

[6] Sairam Kotari and V. Gopinath, "Static and dynamic examination on tatra body", vol 2, ISSN: 2249-6645 division of mechanical building, QIS school of designing, Andhra Pradesh.

[7] Introduction to case plan, by Keith J. Wakeham, Memorial University of Newfoundland And Labrador.

[8] Chetan J. Choudhury and akash lodhi, "Static burden examination of TATA-407 case" - a methodology, ISSN 22315063,Mechanical office, K.D.K. school of designing , Maharashtra.

[9] PSG Design Data Book for Standard Data-M/sKalaikathir Achchagam, Coimbatore2004 